\title{
A ALFABETIZAÇÃO SOB O PONTO DE VISTA HISTÓRICO E METODOLÓGICO
}

\author{
Reginaldo José Barboza
}

Faculdade de Ensino Superior e Formação Integral - FAEF/ACEG, Curso de Pedagogia, Garça, SP, E-mail: reginaldoj3@hotmail.com

\begin{abstract}
RESUMO
A alfabetização é umas das etapas fundamentais na vida de uma pessoa, pois, a partir do momento em que um sujeito aprende a decifrar o código alfabético e principalmente a entendêlo, de maneira que consiga interpretar o que lê, ele começa a se tornar o sujeito de sua própria história. Dessa forma, o objetivo do presente artigo diz respeito a um breve levantamento histórico sobre a alfabetização bem como a descrição de alguns métodos implícitos nela. Para tanto, foi realizada uma pesquisa bibliográfica acerca deste tema e a partir disso concluiu-se o quanto é fundamental ao educador conhecer a evolução da alfabetização e a sua aplicação metodológica. O educador é um mediador do processo de aprendizagem do educando e, assim sendo, deve registrar e diagnosticar as dificuldades apresentadas cuidando sempre para que a sua intervenção pedagógica não provoque bloqueios nesse processo.
\end{abstract}

Palavras-chave: Alfabetização. Métodos. Aprendizagem.

\section{THE BASIC LITERACY IN THE VIEWPOINT HISTORY AND METHODOLOGY}

\begin{abstract}
Basic literacy is one of the key stages in the life of a person. For, from the moment a subject learns to decipher the code letter and especially to understand it, so he can interpret what you read, it starts to become the subject of his own history. However, the purpose of this article it concerns a brief historical survey about literacy and the description of some methods implicit in it. Therefore, a literature search was conducted on this topic and concluded from that is how it is fundamental to the educator to know the evolution of literacy and its methodological application. The teacher is a mediator of the student's learning process and, therefore, must register and diagnose the difficulties presented when caring for their pedagogical intervention does not cause blockages in the process.
\end{abstract}

Keywords: Basic Literacy. Methods. Learning. 


\section{INTRODUÇÃO}

O desenvolvimento da alfabetização corresponde diretamente à libertação de uma pessoa, pois, a partir do momento em que um sujeito aprende a decifrar o código alfabético e principalmente entendê-lo, de maneira que consiga interpretar o que lê, ele começa a se tornar sujeito de sua própria história.

Indubitavelmente, em nossa sociedade um sujeito alfabetizado, em comparação com um analfabeto, têm condições mais apropriadas de disputar uma vaga de emprego, de frequentar um curso e assim por diante. Ou seja, a alfabetização é essencial para o indivíduo melhorar a sua condição de vida. Nesse caso, a leitura e a escrita estão entre os mais poderosos meios de comunicação, elas nos permitem entender e apreciar as ideias dos outros permitindo assim, de forma gradual, que ocorra a saída do senso comum para um conhecimento mais elaborado.

Nesse sentido, este trabalho apresenta uma pesquisa bibliográfica acerca deste tema tendo como objetivo principal a realização de um breve levantamento histórico e metodológico sobre a alfabetização.

\section{ALGUNS DOS PRINCIPAIS ASPECTOS DA LEITURA E DA ESCRITA NA ANTIGUIDADE}

Destacaremos brevemente a seguir os primeiros sistemas de escrita da Antiguidade e, em seguida, faremos uma descrição a respeito do uso das cartilhas e métodos de alfabetização em nossa atualidade.

Podemos possivelmente pensar a respeito do processo de alfabetização partindo do princípio de que esta surgiu na Antiguidade por meio da representação gráfica do mundo, através de um desenho e da representação gráfica de uma palavra, através da escrita. Nesse sentido, observamos que Cagliari (1996) usa de uma linguagem metafórica para ilustrar como isso poderia ter ocorrido:

(...) quem inventou a escrita foi a leitura: um dia, numa caverna, o homem começou a desenhar e encheu as paredes com figuras, representando, animais, pessoas, objetos e cenas do cotidiano. Certo dia recebeu a visita de alguns amigos que moravam próximo e foi interrogado a respeito dos desenhos. Queriam saber o que representavam aquelas figuras e por que ele as tinha pintado nas paredes. Naquele momento, o artista começou a explicar os nomes das figuras e a relatar os fatos que os desenhos representavam. Depois, à noite, ficou pensando no que tinha acontecido e acabou descobrindo que podia "ler" os desenhos que tinha feito. Ou seja, os desenhos, além de representar objetos da vida real, podiam servir também para representar palavras que, por sua vez, se referiam a esses mesmos objetos e fatos na linguagem oral. A humanidade descobria assim que, quando uma forma gráfica representa o mundo, é apenas um desenho; mas, quando representa uma palavra, passa a ser uma forma de escrita (...). (CAGLIARI, 1996, p.13, 14).

Assim sendo, de acordo com o presente autor (CAGLIARI, 1996), o homem, desde seus primeiros tempos de existência, procurou expressar de alguma forma sua maneira de viver e entender o mundo. Como ele não conhecia outra forma de linguagem começou então a desenhar objetos e a registrar os fatos que ocorriam na época através deles. Dessa forma, ele descobriu que o desenho era uma forma gráfica de representar o mundo. Depois, com a aparição de novos e diferentes povos, cada um foi fazendo suas representações de acordo com os interesses políticos, financeiros, religiosos e culturais.

Tradicionalmente, era comum, e de certa maneira até hoje é, um indivíduo aprender a ler sem necessariamente ter ido para a escola, já que não pretendia se tornar um escriba. A 
curiosidade, certamente, levava muita gente a ler para lidar com os negócios, o comércio e até mesmo para ler as obras religiosas ou obter informações culturais da época. A alfabetização, nesses casos, ocorria a partir da transmissão de conhecimentos relativos à escrita de quem os possuía para quem queria aprender. Aprender a decifrar a escrita, ou seja, a ler relacionando os caracteres às palavras da linguagem oral, devia ser o procedimento comum (CAGLIARI, 1996, p.23).

Ainda sobre a importância da alfabetização na antiguidade, Rizzo (2005) afirma que o ensino da leitura e da escrita enfatizava somente o domínio do alfabeto, nesse período ensinavase ao indivíduo apenas o nome e as formas das letras. Esse processo iniciava-se pelo reconhecimento oral do nome de cada letra. Esse procedimento era bastante repetitivo e demorado sem qualquer preocupação de ligação com os significados das palavras lidas. Para esse autor (2005), nesta época os alunos eram alfabetizados de modo em que aprendiam a ler algo escrito e depois copiavam ou somente transcreviam. Esse processo de leitura e cópia era considerado o segredo da alfabetização.

A escrita que temos hoje, o alfabeto com o qual (re) construímos graficamente nosso olhar, com o qual podemos dizer das coisas e dos outros, é resultante "de longos anos de história da escrita e decorrente de sua necessidade de registrar fatos, ideias e pensamentos" (RIZZO, 2005, p.13).

No final da década de 1910 o termo "alfabetização" passou a ser utilizado para se referir ao ensino inicial da leitura e da escrita. Dessa forma, a alfabetização correspondia ao aprendizado do alfabeto e de sua utilização como código de comunicação. E é definida como um processo não apenas da aquisição de habilidades mecânicas como a codificação e decodificação, mas sim da capacidade de interpretar, compreender, criticar, ressignificar e produzir conhecimento (MORTATTI, 2000).

A partir do que foi observado até o presente momento é possível concluir que a alfabetização favorece o progresso da socialização do indivíduo, possibilitando o estabelecimento de novos tipos de trocas simbólicas com outros indivíduos, acesso aos bens culturais e as facilidades oferecidas pelas instituições sociais. Ou seja, a alfabetização resulta no exercício consciente da cidadania e do desenvolvimento da sociedade.

\section{CARTILHAS: UM PARADIGMA DA HISTÓRIA DA ALFABETIZAÇÃO BRASILEIRA.}

Não há como falar de alfabetização brasileira sem citar algumas cartilhas tais como: a Cartilha Sodré, Caminho Suave, Cartilha da infância etc., embora em épocas diferentes, elas, segundo Cagliari (1996), apresentam a mesma estrutura, ou seja, são compostas por letras, sílabas, palavras e frases curtas para facilitar a aprendizagem da leitura e da escrita.

As primeiras cartilhas escolares, até cerca de 1950, davam ênfase à leitura. O importante nesse momento era ensinar o "abecedário". A leitura era feita através de exercícios de decifração e de identificação de palavras, por meio dos quais os alunos aprendiam as relações entre as letras e sons, seguindo a ortografia da época (CAGLIARI, 1996, p. 31).

A cartilha baseada na leitura passou por uma mudança radical a partir dos anos de 1950, quando a escola começou então a se dedicar à alfabetização dos alunos pobres, carentes de recursos materiais e culturais da vida familiar, que empregavam dialetos diferentes da fala culta. A ênfase passou a ser dada à produção escrita pelo aluno e não mais à leitura. O importante era aprender a escrever as palavras, a atividade escolar deixou de privilegiar a aprendizagem e passou a cuidar quase que exclusivamente do ensino, ou seja, àquilo que o professor deveria fazer em sala de aula (CAGLIARI, 1996).

A cartilha enfatizava o alfabeto, as palavras-chave, as sílabas geradoras e os textos já estudados. As famílias de letras passaram a ser estudadas numa ordem crescente de dificuldades. Completadas todas as letras, o aluno começava a ler seu livro de leitura, também programado de 
maneira a ter dificuldades crescentes, libertando aos poucos o aluno da cartilha levando-o a ler autores de textos infantis. Essa cartilha já trazia em si o esquema de todas as outras cartilhas que apareceram depois, até recentemente, caracterizando a alfabetização pelo estudo da escrita. (CAGLIARI, 1996).

Para Mortatti (2000) o processo de nacionalização do livro didático no Brasil acontece desde o final do século XIX, no qual as cartilhas eram produzidas por brasileiros e adaptadas à realidade brasileira.

De acordo com Mortatti (2000), as primeiras cartilhas brasileiras se baseavam nos métodos sintéticos, iniciando assim o ensino da leitura e da escrita com a apresentação das letras e seus nomes. Em seguida eram ensinadas as famílias silábicas e a ler palavras formadas com essas sílabas, enfim eram ensinadas apenas frases isoladas. Em relação à escrita, enfatizavam-se a caligrafia, a cópia, os ditados e a formação de frases, a ortografia e o desenho correto das letras. Contudo, observamos que:

A partir do início da década de 1980, essa tradição passou a ser sistematicamente questionada, em decorrência de novas urgências políticas e sociais que se fizeram acompanhar de propostas de mudança na educação, a fim de se enfrentar, particularmente, o fracasso da escola na alfabetização de crianças. Como correlato teóricometodológico da busca de soluções para esse problema, introduziu-se no Brasil o pensamento construtivista sobre alfabetização, resultante das pesquisas sobre a psicogênese da língua escrita desenvolvidas pela pesquisadora argentina Emilia Ferreiro e colaboradores. Deslocando o eixo das discussões dos métodos de ensino para o processo de aprendizagem da criança (sujeito cognoscente), o construtivismo se apresenta, não como um método novo, mas como uma "revolução conceitual", demandando, dentre outros aspectos, abandonarem-se as teorias e práticas tradicionais, desmetodizarse o processo de alfabetização e se questionar a necessidade das cartilhas. (MORTATTI, 2006, p. 10).

Assim, apesar do surgimento de obras classificadas como construtivistas, que tinham, como já vimos, em sua proposta educacional a aplicação dos ensinamentos de psicogênese da língua escrita de Emília Ferreiro e Ana Teberosky (1985), o processo de alfabetização continuava sendo programado mediante o uso do livro didático. Em outras palavras, buscava-se a junção da metodologia aplicada nos livros didáticos com a teoria de aprendizagem construtivista formando desta maneira uma espécie de "cartilha construtivista". Existiam ainda, segundo Mortatti (2006), os defensores das tradicionais cartilhas, ou seja, queriam constituir paradoxalmente um método eclético ou misto entre a cartilha e as teorias construtivistas.

Há de se considerar, conforme afirma Mortatti (2000), que existe um paradoxo quanto à produção de cartilhas "construtivistas" ou "socioconstrutivistas" ou "sociointeracionistas", já que de acordo com essas teorias a aprendizagem do aluno, ou ainda, a construção do seu conhecimento não se pauta por um "método" ou por algo pronto e acabado, como normalmente é o caso de uma cartilha. Ainda que os professores afirmem que elas serviriam apenas para a consulta ou para a preparação de suas aulas isso não corresponderia à proposta "construtivista" e/ou "interacionista". Ainda, de acordo com essa autora (2000), não é producente que o professor deixe de usá-la (cartilha) no seu sentido físico e continue desenvolvendo suas atividades cotidianas de maneira mecanizada e desinteressante. Ou seja, apesar de os alunos não possuírem uma cartilha nas mãos, é comum os professores passarem na lousa todo o conteúdo e os alunos copiarem em seus cadernos fazendo disso, portanto, "outra" forma de cartilha. 
Para Ferreiro (2006), as cartilhas oferecem um universo artificial e desinteressante. As palavras isoladas, aparentemente simples e sonoras encontradas nas cartilhas, do ponto de vista da assimilação das crianças, simplesmente não se ligam a nada. Portanto, a presente autora (2006) recomenda a utilização de textos sobre as atualidades, livros, histórias, jornais e revistas para estimular a compreensão da função social da escrita. Nesse sentido, Ferreiro (2006) garante portanto que é fundamental o professor trabalhar com textos que tenham significados para a criança e de valor social.

\section{ALGUMAS CONSIDERAÇÕES SOBRE A TEORIA DA APRENDIZAGEM CONSTRUTIVISTA PARA A ALFABETIZAÇÃO}

No Brasil, a história da alfabetização está atrelada aos métodos de ensino, principalmente desde o final do século XIX, e isso indubitavelmente tem gerado várias teorias para um mesmo problema: a dificuldade das crianças em aprender a ler e a escrever, principalmente em escolas públicas.

Assim sendo, na história da alfabetização do Brasil há momentos marcantes em relação aos métodos de ensino inicial da leitura e da escrita, e ao contrário de aplicação de "métodos" temos a teoria da aprendizagem construtivista para a alfabetização desenvolvida por Ferreiro e Teberosky (1985). Entretanto, antes comentarmos sobre o construtivismo é conveniente apontarmos aqui alguns dos principais métodos de alfabetização utilizados historicamente para ensinar a criança a ler e a escrever.

Inicialmente, temos o método sintético em que, de acordo com Mortatti (2000), a aprendizagem da leitura e da escrita se baseava em uma questão mecânica, tratava-se de adquirir uma técnica para meramente decifrar o texto. O processo de aprendizagem da leitura era visto como uma associação entre respostas sonoras e estímulos gráficos. Exemplo: O professor iniciava ensinando o traçado isolado de cada letra, e às vezes só partia dela, sem se preocupar com o significado da palavra como um todo ou do contexto desta em uma frase.

O outro método é o analítico que, conforme Mortatti (2000), surgiu em oposição ao método sintético. O método analítico encaminha o aluno para a realização de uma análise do todo que pode ser uma frase ou uma palavra para chegar às partes mais simples como as sílabas e do conhecido para o desconhecido. Exemplo: A professora inicia o seu trabalho de alfabetização com os alunos começando por uma determinada frase (João trabalha em uma fábrica de doce) e a partir daí dividi-a em partes menores extraindo as palavras (trabalha) e chegando as unidades mais simples como as sílabas (tra-ba-lha).

Já outro método, o fonético, tem como propositor o linguista americano Bloomfield, que defende a aquisição da linguagem como um processo mecânico (MORTATTI, 2000). O método fônico tem como objetivo fazer com que a criança internalize padrões regulares de correspondência entre o som e a soletração, através da leitura de palavras das quais ela venha a inferir as correspondências entre soletração/som. Exemplo: A professora apresenta na lousa uma palavra significativa (ambulância) vinculada a uma imagem que representa esse objeto. Em seguida ela enfatiza, lendo em voz alta conjuntamente com os alunos, a relação entre o grafema e o fonema de cada sílaba ou letra (Am-bu-lân-ci-a, demonstrando que esta possui 5 sílabas e 10 letras). Outro exemplo pode ser dado a partir do momento em que o aluno completa a letra que estaria faltando na palavra (_bu_ci__), neste caso a professora poderia ir pronunciando juntamente com os alunos os sons e as sílabas ou letras. Além de se trabalhar com a grafia e com o som a professora já destaca também situações de aprendizagens que envolvem: consoantes e vogais, letras maiúsculas e minúsculas, letra cursiva e em bastão e assim por diante.

Entretanto, em oposição à aplicação de tais métodos mencionados acima, podemos dizer que, de acordo com a teoria da aprendizagem construtivista, inspirada na concepção piagetiana de epistemologia genética (FERREIRO e TEBEROSKY, 1985), o professor, ao invés de apontar "os 
erros" e fornecer a "resposta correta", deve questionar as respostas oferecidas pela criança e desta maneira fazer com que ela perceba as suas limitações. Ou seja, é importante permitir que a criança desenvolva suas próprias teorias e hipóteses sobre o que está sendo investigado.

Ferreiro, acerca de suas pesquisas experimentais, discute em suas obras "Psicogênese da língua escrita", desenvolvida em conjunto com Ana Teberosky (1985), "Reflexões sobre alfabetização" (2001) e "Alfabetização em processo" (2006) as concepções da criança sobre o sistema de escrita.

Antes de Emília Ferreiro as discussões a respeito da alfabetização giravam em torno apenas dos métodos utilizados: analíticos, sintético ou fonético. Para muitos educadores a alfabetização inicial era somente a relação entre o método utilizado e o estado de "maturidade" ou de "prontidão" da criança, ou seja, se a criança estava pronta, se ela tinha compreensão suficiente e se estava na idade certa para aprender. Mas, conforme essa autora (2001) os métodos não oferecem mais do que sugestões ou conjunto de proibições. Assim sendo, as teorias desenvolvidas por Emília Ferreiro e sua colaboradora Ana Teberosky (1985) deixam de fundamentar-se em concepções mecanicistas sobre o processo de alfabetização, para seguir os pressupostos construtivistas de Piaget.

A revolução no processo de alfabetização ocorre justamente no fato de se explicar "como as crianças aprendem": elas passam por etapas, até se apossarem do código linguístico e desta maneira dominá-lo. Nesse contexto, o objetivo primordial de Ferreiro e Teberosky (1985) jamais foi rotular as crianças e sim orientar os educadores frente às evoluções cognitivas de seus alunos.

Devemos considerar que Ferreiro não criou um método de alfabetização, como os demais mencionados acima, e sim estudou como se realiza a construção da linguagem escrita na criança. Para esta autora, a escrita não resulta de simples cópia, mas deve ser um processo de construção pessoal. (FERREIRO, 2001).

Tanto as descobertas epistemológicas de Piaget (1971) como as de Ferreiro (1985) na área educacional nos levam a conclusão de que as crianças desempenham um papel ativo no processo de aprendizagem, ou seja, elas constroem o próprio conhecimento, e o professor serve com um provocador para que isso ocorra.

Assim sendo, há uma mudança de concepção conceitual onde o foco da alfabetização muda da escola para o aluno que aprende. Há um deslocamento do eixo das discussões dos "métodos de ensino" para o processo de aprendizagem da criança. E o construtivismo passa a ser apresentado não como um "novo método", mas como uma revolução conceitual, levando os educadores a abandonarem as teorias e práticas tradicionais, "desmetodificando" o processo de alfabetização e questionando a necessidade do uso das cartilhas.

No entanto, é necessário levarmos em consideração as críticas elaboradas por Soares (2003) quanto a essa mudança de concepção conceitual, ou seja, de que a partir do surgimento da proposta construtivista não seria mais preciso existir método de alfabetização. A presente autora reconhece o fato de que a criança "vai construindo hipóteses a respeito da escrita e, com isso, vai aprendendo a ler e a escrever numa descoberta progressiva" (SOARES, 2003, p. 17). Por um lado, portanto, isso implica que não podemos descartar a ideia de que essa criança vai construindo o seu conhecimento. Mas, por outro lado, também não podemos desmerecer a importância da praticidade dos métodos ou de técnicas da escrita que auxiliam as professoras na relação do ensino-aprendizagem.

Para tanto, observamos que:

(...) os métodos viraram palavrões. Ninguém podia mais falar em método fônico, método silábico, método global, pois todos eles caíram no purgatório, se não no inferno. Isso foi uma conseqüência errônea dessa mudança de concepção de alfabetização. Por equívocos e por inferências falsas, passou-se a ignorar ou a menosprezar a especificidade da aquisição 
da técnica da escrita. Codificar e decodificar viraram nomes feios. 'Ah, mas que absurdo! Aprender a ler e escrever não é aprender a codificar e decodificar'. Aí é que está o erro. Ninguém aprende a ler e a escrever se não aprender relações entre fonemas e grafemas para codificar e para decodificar. Isso é uma parte específica do processo de aprender a ler e a escrever. Lingüisticamente, ler e escrever é aprender a codificar e a decodificar. (SOARES, 2003, p. 17).

Enfim, Soares (2003) não considera que haja incompatibilidade na postura do alfabetizador em adotar a teoria construtivista e um determinado método, já que ambos se complementam. Conforme a concepção pedagógica dessa autora, antigamente tínhamos o método sem a teoria e atualmente possuímos a teoria sem um método, nesse caso, "(...) é preciso ter as suas coisas: um método fundamentado na teoria e uma teoria que produza um método". (SOARES, 2003, p.17).

\section{CONCLUSÃO}

Ao realizamos esse artigo sob uma pesquisa bibliográfica pudemos inferir alguns dados que propiciam condições para compreendermos melhor alguns aspectos relevantes sobre o processo de alfabetização.

Após abordamos brevemente a história da alfabetização observamos que os estudos realizados nas últimas décadas fazem com que haja mudanças na forma de compreender o processo de alfabetização. Muda-se o foco de como se ensina para descrever como se aprende. Desta forma foi possível compreender que a alfabetização não é um processo em que se memoriza para aprender a ler e a escrever. $O$ aluno precisa constituir um conhecimento de natureza conceitual, ele precisa compreender não só o que a escrita representa, mas também de que forma ela representa graficamente a linguagem.

No entanto, o ponto de partida para a ação pedagógica deve ser a criança, é importante conhecer a sua história e considerar o meio onde vive e se desenvolve. Cabe à escola, ao professor, proporcionar meios para ativar o interesse da criança e assim ampliar seus conhecimentos prévios e caminhar para o "novo". Muitos de nossos alunos não recebem esse incentivo por parte das famílias e esperam que tudo se resolva na escola.

É importante ressaltar a extrema necessidade de o professor conhecer a evolução da escrita infantil, sendo cúmplice desses momentos de aprendizagem, registrando as mudanças por menor que elas sejam, diagnosticando as dificuldades apresentadas para que a sua intervenção pedagógica não provoque bloqueios no progresso da aprendizagem. É um trabalho difícil porque as crianças não avançam juntas ou ao mesmo tempo umas com as outras: apresentam diferenças no ritmo da aprendizagem e também trazem vivências diferentes que devem ser respeitadas.

Se a escola for capaz de colocar em prática um ensino baseado no respeito ao aluno, considerando o como parceiro social e cujo conteúdo não escamoteie as relações sociais e as condições econômicas e materiais, historicamente determinadas, ela estará desta maneira cumprindo um dos seus papéis: preparando-o para uma análise crítica da realidade e dos modelos sociais. Sobre isso, o papel que o professor desempenha, buscando como já vimos um método apropriado, planejando os conteúdos e os objetivos do ensino da leitura e da escrita pautado também na teoria construtivista representa algo fundamental na formação do aluno. Assim, estaremos a caminho de romper com "velhos paradigmas" metodológicos propiciando um ensino de qualidade instrumentalizando o aluno para ler e escrever de forma mais apropriada.

\section{REFERÊNCIAS}

CAGLIARI, Luiz Carlos. Alfabetização sem o Bá-Bé-Bi-Bó-Bu. São Paulo: Editora Scipione, 1999. 
FERREIRO, Emília. Alfabetização em processo. São Paulo: Editora Cortez, 2006.

FERREIRO, Emília. Reflexões sobre alfabetização. Trad. Horacio Gonzáles. 24. ed. Sao Paulo:

Cortez, 2001. V14 (Coleção Questões da Nossa Época).

FERREIRO, Emília; TEBEROSKY, Ana. Psicogênese da língua escrita. Porto Alegre: Artes Médicas, 1985.

MORTATTI, Maria do Rosário. Os sentidos da alfabetização. São Paulo: Editora UNESP, 2000.

- História dos métodos de alfabetização no Brasil. 2006. Seminário Alfabetização e Letramento em Debate. Secretaria de Educação Básica do Ministério da Educação. Brasília. Disponível em: http://portal.mec.gov.br/seb/arquivos/pdf/Ensfund/alf_mortattihisttextalfbbr.pdf. Acesso em: 19 set. 2016.

PIAGET, Jean William Fritz. A Epistemologia Genética. Trad. Nathanael C. Caixeira. Petrópolis: Vozes, 1971.

RIZZO, Gilda. Alfabetização Natural. 3. ed. Rio de Janeiro: Editora Bertrand Brasil, 2005.

SOARES, Magda. A reinvenção da Alfabetização. Revista Presença Pedagógica, Belo Horizonte, v. 9, n. 52, p. 1-21, jul/ago de 2003. 